Copyright (C) 2021 by Cherkas Global University

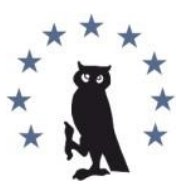

Published in the USA

Voennyi Sbornik

Has been issued since 1858 .

E-ISSN: 2409-1707

2021. 9(2): 70-75

DOI: $10.13187 / v s .2021 .2 .70$

https://vs.cherkasgu.press

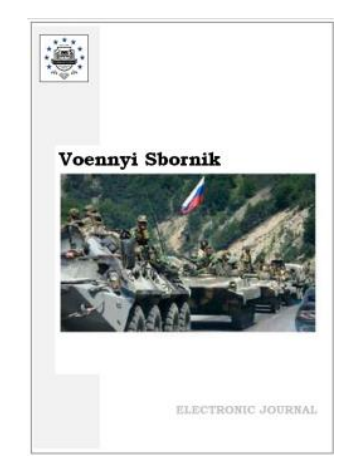

\title{
Articles
}

\section{The Last Years of the Black Powder Era}

Kent R. Crawford a

${ }^{a}$ Gunnery Fire Control Group, USA

\begin{abstract}
In previous works, we developed a mathematical model of the internal ballistics of a muzzleloading smooth-bore gun and made its software implementation. Model testing has shown that our understanding of the intra-ballistic processes of this type of weapon requires serious correction. One of the defining parameters is the geometry of the powder grain. This paper reviews the information available in the literature on this issue. It is concluded that in most works on the geometry of the grain is not reported, due to the fact that the grains had some kind of intuitively justified form. Based on the analysis of the technology for producing grain gunpowder in the first half of the 19th century, it was concluded that this shape is similar to the shape of pebbles on the beach.
\end{abstract}

Keywords: gunpowder, black powder, grain, technology, grain's form.

\section{Introduction}

At the beginning of 2021, we submitted a large article to the journal "Chemical Physics and Mesoscopy" on the possibility of simulating the combustion of grains of unknown shape (Crawford, Mitiukov, 2021). The basis of this article had a practical application in the form of modeling the processes occurring in muzzle-loading smooth-bore guns. However, the editors decided to remove almost the entire historical part, leaving only what concerns the models and simulation results. This paradox is already familiar to us: historians do not understand complex models, and engineers do not understand the need to model systems 150 years ago. In this work, we partially compensate for this injustice, giving our historical excursion in full.

\section{Results and discussion}

Gunpowder was not new in 1588 when the Duke of Medina Sidonia expressed pleasure that the Spanish Armada had been provided with 'corned' powder for its guns rather than the 'meal' powder normally used, demonstrating a rudimentary understanding that grain size mattered for artillery.

Black powder is a mechanical mixture of three component parts, charcoal, niter and Sulphur. The percentages of each varied over time, but by mid-186os the most widely accepted proportions were $75 \%, 15 \%$ and $10 \%$ by weight. These were thoroughly mixed with a certain amount of water, and then allowed to dry. This cake was then crumbled into a fine powder, put into barrels and shipped. It was discovered that by subjecting the moist cake to pressure, a denser powder resulted, which performed better. And the realization that grain size mattered to intended use, a method of sorting the crumbled cake was devised. In simple terms, this involved a multi-level sieve with different diameter holes (mesh) at each level. 
Table 1. Mesh diameters for black powder in 1845 U S Army (inch)

\begin{tabular}{|l|c|c|c|c|c|c|c|c|}
\hline № of sieve & 1 & 2 & 3 & 4 & 5 & 6 & 7 & 8 \\
\hline For cannon powder & 0.10 & 0.085 & 0.07 & & & & & \\
\hline For musket powder & - & - & 0.07 & 0.06 & 0.05 & & & \\
\hline For rifle powder & - & - & - & - & - & 0.035 & 0.03 & 0.025 \\
\hline
\end{tabular}

Using the mesh diameters of the U.S Ordnance Department of 1845 as representative of the state of the art, what the image signifies is the crumbled cake is sorted by use. A grain that passed through the 0.1 -inch $(2.54 \mathrm{~mm})$ but stood on the 0.085 -inch $(2.159 \mathrm{~mm})$ was intended for large bore artillery. Grain size would be between 0.1 and 0.085 inch. The next level, less than 0.085 but more than 0.07, was for small bore artillery, and so on. Powder of less than 0.025-inch was for pistols and filler for shells.
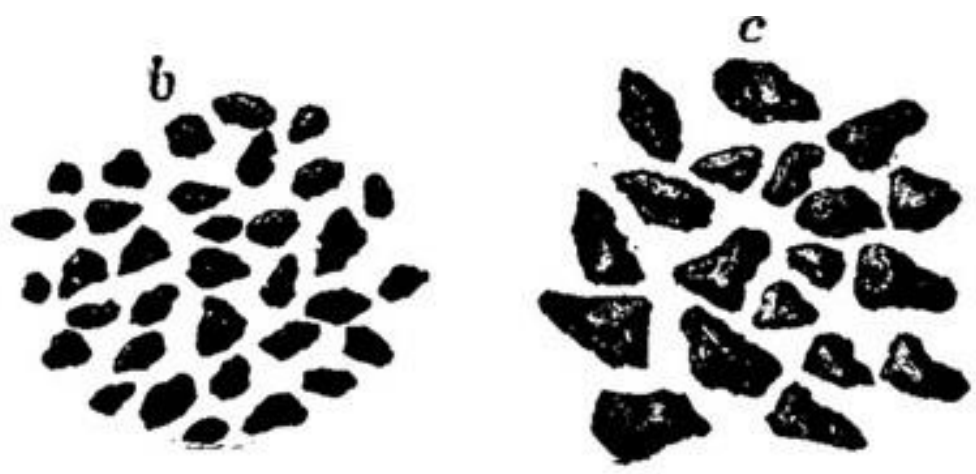

Fig. 1. Black powder grain flakes

The grains of powder from the 'meshing' process, while being of roughly the same size, were hardly the same shape, as exemplified in the illustration. Sharp corners, small spikes and thin segments or protrusions had an effect on the ignition and subsequent burn. These were less of a problem with small grains, but as grain size grew larger to meet the demands of artillery, such 'irregular' ignition demanded attention.

This led to two additional processes to the production of gunpowder. The first was known as 'dusting.' A quantity of powder was put into a barrel, which was then rotated for a period of time, which varied considerably from one country to another. The French reportedly turned their powder for an extended period, producing almost spherical grains. The 'dust' residue was carefully collected and recycled into the production process.
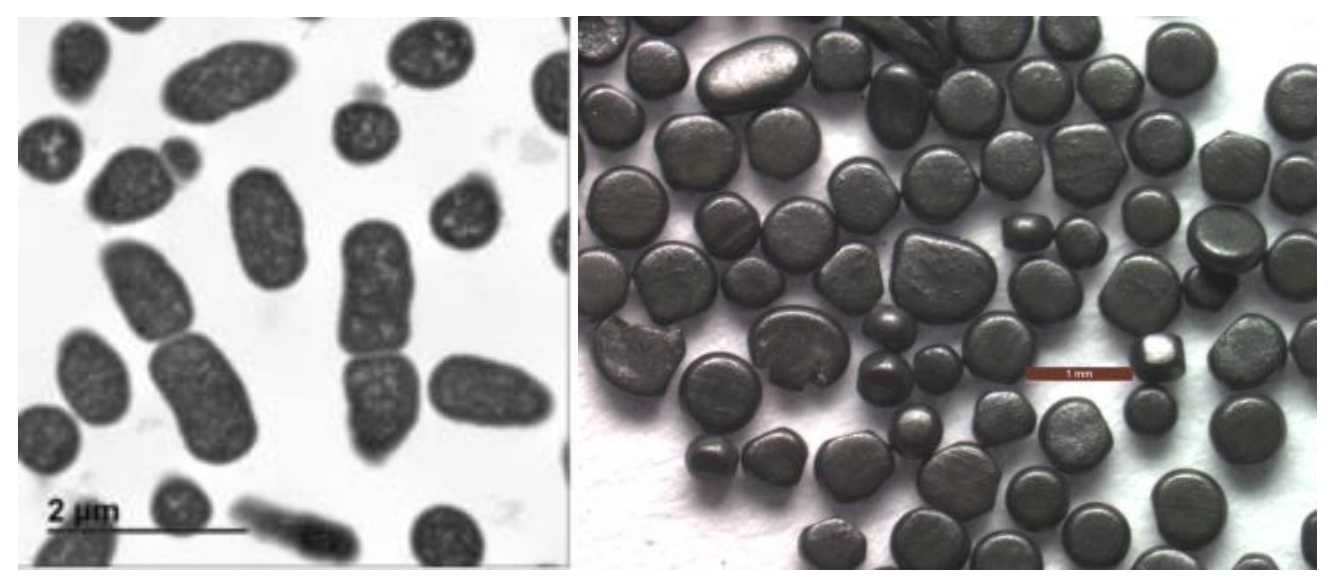

Fig. 2. Dusted gunpowder grains (on left), very heavily glazed gunpowder (on right)

The second process is known as 'glazing,' and has much in common with dusting. A large barrel of powder is turned rather slowly, say 12 revolutions per minute, for a period of many hours, 
so that the powder shifts around, coming into contact with the inside surface of the barrel, and becomes 'polished.' Often very finely powdered graphite is added to coat the grains. This process imparts a number of advantages; it increases the density of the grains by a slight amount, it makes the grains more resistant to moisture, it aids in 'regular' ignition by providing a more uniform surface, and 'weak' or 'inferior' grains will break up.

Dusting and Glazing can be combined into a single operation, though the best results seem to come from separate functions.

In 1858, Thomas J. Rodman, already known for the development of hollow-casting of large bore cannon, turned his attention to gunpowder. He performed many experiments, the results of which were published in 1860. Two of these are particularly important to the future of black powder.

Having developed a 'crusher gauge' to measure gas pressure, he acquired an old $42 \mathrm{pdr}$ (7-inch, $178 \mathrm{~mm}$ ) smoothbore. Holes were drilled through the wall, one at the bottom of the bore, and at intervals of 14-inches to the muzzle, into which a pressure gauge was screwed. DuPont provided special powder, beginning with a grain of 0.1 -inch and proceeding at one tenth inch intervals to a grain of 1-inch. Charges of precisely the same weight were prepared for each grain size, and standard bolts served as the projectiles.

The intent was to measure the effect of grain size on the gas pressures in the gun. Trial results were carefully recorded, and were graphed. The resulting 'pressure curves' influenced gun design for decades, one of the first being the Dahlgren shell guns. And Rodman's own guns were designed for a large grain powder. Known as 'Columbiad Powder,' the initial grain size was 0.4-inches, and the Confederates increased this to o.6-inches. While the Rodman and Dahlgren guns were cast to reflect the pressure curve, one can see the influence in the built-up guns produced by Armstrong, Blakely, Krupp, Whitworth and many others.
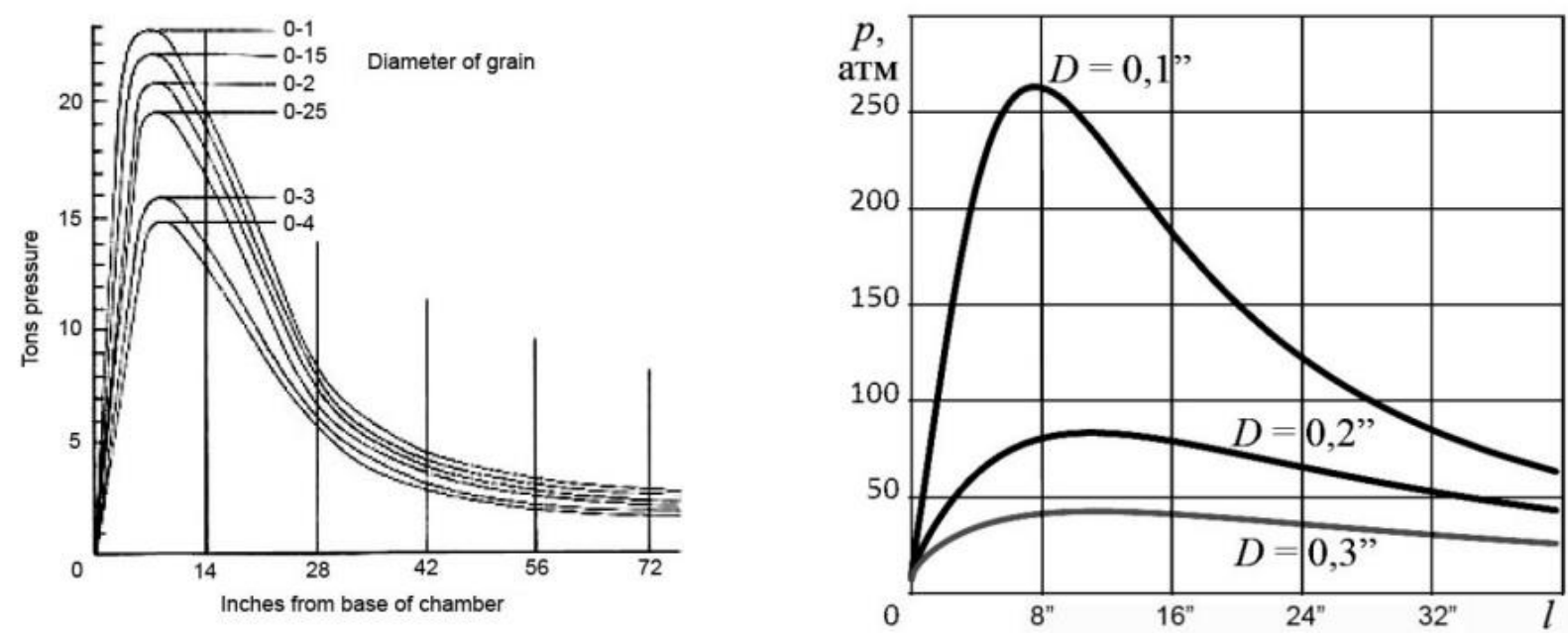

Fig. 3. Grain pressure curves (Mitiukov, Crawford, 2012)

Another important experiment was intended to assess the effect of powder density on pressure and initial velocity. For this he used a 9pdr (3.67-inch, $93.22 \mathrm{~mm}$ ) smoothbore gun. Both DuPont and Hazard provided ten powders of the same grain sizes, the difference being the density (specific gravity); DuPont 1.71 and Hazard 1.55. The charges were 1 1/4 pound. A pressure gauge was installed at the bottom of the bore, and the muzzle velocity was measured by a gun-pendulum and a Navez electro-ballistic machine. The trial involved three fires with each of the ten grain sizes for each producer.

The mean results were startling, and conclusive. The lower density Hazard produced $131 \%$ more pressure $17 \%$ more initial velocity and $9 \%$ more range. In detail, the higher density DuPont powder not only burned slower, which would have rewarded a higher initial velocity to a longer barrel, but also was more uniform in its performance.

Rodman's experimental work also produced a different line of powder development. He had theorized that the best form for a propellant charge was a 'full bore cake.' This was a compressed disk of powder with a single perforation in the center, of a diameter slightly less than the caliber of 
the gun. Charge weight could be increased by adding another disk. Test shoots proved the efficacy of the theory, but also exposed the disadvantages; that the disks were too fragile for use in the field, and the loss of muzzle velocity, pound for pound of powder, rendered them less attractive to the Ordnance Department. Robert Ogden Doremus suggested to Rodman and DuPont in early 1860 that a prismatic shape would be stronger and more versatile. From this came the most successful and long-lived form for a propellant; Prismatic.
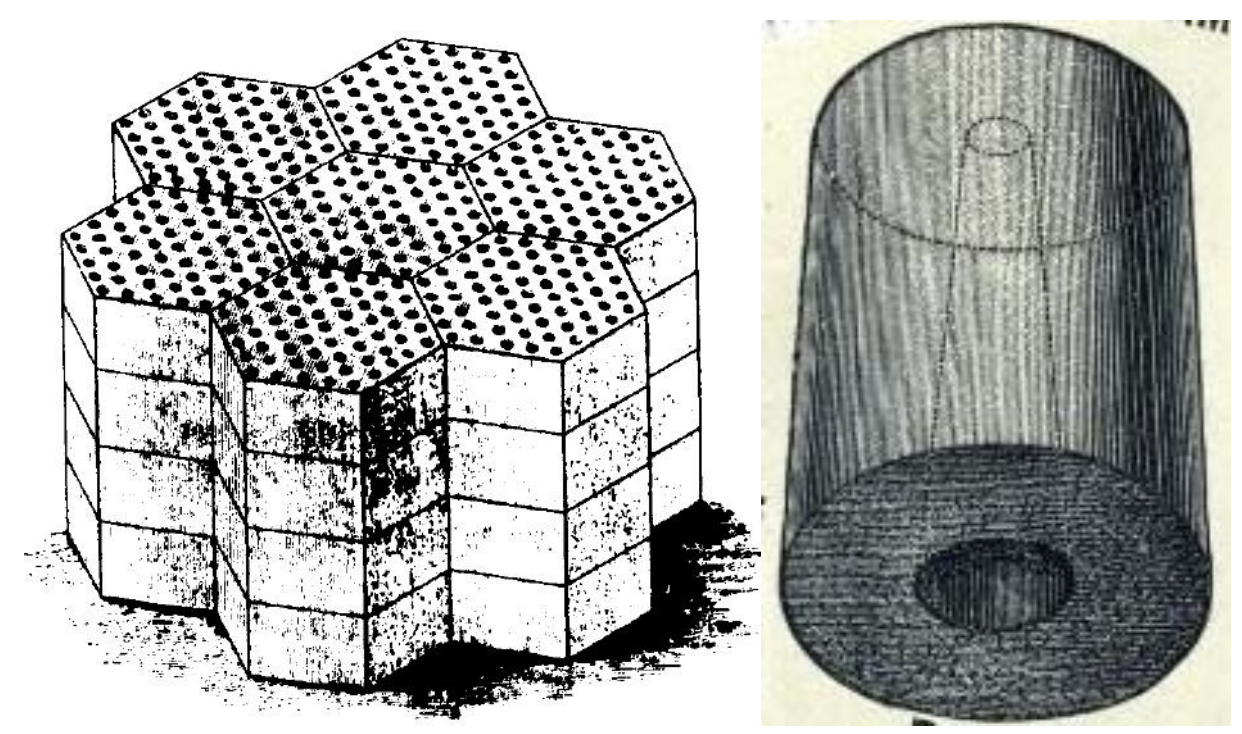

Fig. 4. Rodman full-bore perforated prismatic cake (on left), pellet $1 \frac{1 / 4}{4}$ inch diameter (on right)

In 1859, before Doremus became involved, Rodman had suggested an alternative; a spherical grain of compressed powder. The advantage for large bore guns was obvious, and the Ordnance Department promptly issued specifications for 'Mammoth' powder. In practice, two sizes were produced; $5 / 8$-ths inch and $7 / 8$-ths inch, initially with a density of 1.71 , which would be increased over time. For the proposed 20inch $(508 \mathrm{~mm})$ gun, spheres 1-inch in diameter. The origin of the cubic form is obscure. It may well be that Blakely obtained a large quantity of 1-inch cubic powder from Curtis \& Harvey in 1863 for use in the huge 12.75-inch guns built for the defense of Charleston, South Carolina. Such a powder was produced by the Confederate Powder Works following receipt of that sent with the two guns. The Mammoth Powder that accompanied a 15-inch Rodman gun to Britain in 1867 was described as about one quarter of a cubic inch, which corresponds well with cubes of 5/8ths inch. The British Royal Navy received Pebble Powder in 1871, a direct copy of the Mammoth powder. Later in the decade, the $\mathrm{RN}$ would receive a larger version of Pebble, 1 1/2 inch cube, and the Italian Navy would receive Fassano Powder, cubes 50mm (1.97-in).

The final advance was another form of molded compressed powder. John Anderson, Chief Inspector of Machinery for the Woolwich Arsenal and Waltham Abbey, devised a machine that would produce a 'pellet' of powder. This was a cylinder $5 / 8$-th inch in diameter and length, with a through perforation $1 / 4$ inch. Curtis and Harvey, one of the leading concerns in the Trade, acquired

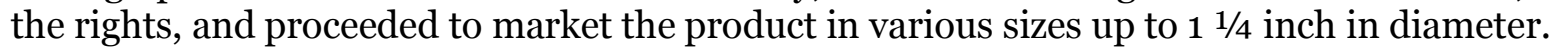

In a sense, the rapid development of black powder may be regarded as an analogy of the Second Industrial Revolution. If US Ordnance may be seen as representing the state of the art, in 1845 a grain size of slightly less than $1 / 10$-th of an inch was the largest grain available for artillery. Fifteen years later, a grain size of $1 / 4$-th inch was considered 'ordinary cannon powder' for small bore pieces, and molded compressed powder was the wave of the future. Twenty more years of scientific and technical progress had relegated flake powder to small bore guns and small arms. By 1890, nitro-cellulose propellants had made gunpowder an historical topic. 
Table 2. Gunpowder grains for artillery

\begin{tabular}{|c|c|c|c|}
\hline \multirow[b]{2}{*}{ System } & \multicolumn{2}{|c|}{ Average grain size } & \multirow[b]{2}{*}{ Information about grain's form } \\
\hline & inches & $\mathrm{mm}$ & \\
\hline \multicolumn{4}{|c|}{ British cannon } \\
\hline British LGP (1865) & 0,071 & 1,803 & ? \\
\hline British LGP (1862) & 0,124 & 3,15 & ? \\
\hline British RLG (1860) & 0,139 & 3,531 & Grains from 0.185in to 0.0935 in \\
\hline British RLG (1865) & 0,147 & 3,726 & ? \\
\hline British RLG No. 2 (1868) & 0,236 & 6,0 & $?$ \\
\hline \multicolumn{4}{|c|}{ Franch cannon } \\
\hline French Repault & 0,079 & 2 & almost spherical, heavily glazed \\
\hline \multicolumn{4}{|c|}{ Other cannons } \\
\hline Spanish cannon & 0,098 & 2,5 & almost spherical, heavily glazed \\
\hline Krupp' cannon & 0,197 & 5 & almost spherical, heavily glazed \\
\hline Krupp' 6 - 10mm & 0,324 & 8.23 & almost spherical, heavily glazed \\
\hline \multicolumn{4}{|c|}{ British Trade } \\
\hline P\&W LGP & 0,091 & 2,3114 & ? \\
\hline P\&W Cannon & 0,122 & 3,0988 & ? \\
\hline Hall\&Sons LGP & 0,130 & 3,302 & $?$ \\
\hline C\&H RLG & 0,147 & 3,744 & $?$ \\
\hline Alliance RLG & 0,148 & 3,759 & $?$ \\
\hline C\&H RLG & 0,158 & 4,001 & $?$ \\
\hline C\&W Large Grain & 0,335 & 8,509 & ? \\
\hline C\&W Giant & 0,590 & 14,986 & $?$ \\
\hline \multicolumn{4}{|c|}{ US cannon } \\
\hline Ordinary cannon & 0,250 & 6,350 & $?$ \\
\hline Large grain & 0,310 & 7,874 & $?$ \\
\hline Columbiad & 0,400 & 10,160 & $?$ \\
\hline \multicolumn{4}{|c|}{ Confederacy cannon } \\
\hline No. 6 ordinary & 0,250 & 6,350 & $?$ \\
\hline No. 7 Large Grain & 0,35 & 8,890 & $?$ \\
\hline No. 8 Columbiad & 0,6 & 15,240 & $?$ \\
\hline No. 9 Columbiad & 0,9 & 22,860 & $?$ \\
\hline
\end{tabular}

\section{Conclusion}

Thus, we see that the technology for producing grain gunpowder from the first half of the 19th century guaranteed the shape of the grain like a pebble on a beach. In this regard, this form was intuitively understandable to witnesses who saw this gunpowder. Therefore, in most literature, the shape of the grains is not indicated.

\section{References}

Barlow, 1878 - Barlow, W.R. (1878). Treatise on Ammunition (1877). London: Her Majesty's Stationery Office.

Benton, 1862 - Benton, J.G. (1862). Ordnance and Gunnery. New York: D. Van Nostrand.

Benton, 1867 - Benton, J.G. (1867). Ordnance and Gunnery. New York: D. Van Nostrand.

Black Powder - Black Powder. [Electronic resource]. URL: http://firearmshistory.blogspot .com.co (2016).

Browne, 1870 - Browne, Ch.O. (1870). Ammunition. A Descriptive Treatise. London: Her Majesty's Stationery Office.

Cooke, 1875 - Cooke, A.P. (1875). A Text-Book of Naval Ordnance and Gunnery. New York: John Wiley \& Son. 
Crawford, Mitiukov, 2021 - Crawford, K.R., Mitiukov, N.W. et al. (2021). About possibility of the combustion's approximating of the 19th century's powder grains by the spherical grains. Chemical physics and mesoscopy. 23(1): 18-26. DOI: 10.15350/17270529.2021.1.2

Gorgas, 1863 - Gorgas, J. (1863). Ordnance Manual for the Confederate Army. Charleston: Evans \& Cogswell. Nostrand.

Holley, 1865 - Holley, A.L. (1865). A Treatise on Ordnance and Armor. New York: D. Van

Mitiukov, Crawford, 2012 - Mitiukov, N.W., Crawford, K.R. et al. (2012). The interior ballistics of muzzle loading smooth-bore canon. Chemical physics and mesoscopy . 14(3): 371-375.

Mordecai, 1845 - Mordecai, A. (1845). Report of Experiments on Gunpowder. Washington: J. and G.S. Gideon.

Sasse, 1985 - Sasse, R.A. (1985). A Comprehensive Review of Black Powder. U.S. Army Ballistic Research Laboratory, Aberdeen Proving Ground, Maryland.

\section{Последние годы эры черного пороха}

Кент Рэнд Крауфорд ${ }^{\text {а }}$

${ }^{a}$ Gunnery Fire Control Group, CШA

Аннотация. В предыдущих работах нами была разработана математическая модель внутренней баллистики дульнозарядного гладкоствольного орудия и произведена ее программная реализация. Как показало тестирование модели, наше понимание внутрибаллистических процессов этого типа орудий нуждаются в серьезной коррекции. Одним из определяющих параметров является геометрия порохового зерна. В данной работе производится обзор имеющейся в литературе информации по этому вопросу. Сделан вывод, что в большинстве работ о геометрии зерна не сообщается, в связи с тем, что зерна имели какую-то интуитивно оправданную форму. На основе анализа технологии получения зернового пороха первой половины XIX века, сделан вывод, что эта форма аналогична форме галек на пляже.

Ключевые слова: орудийный порох, черный порох, зерно, технология, форма зерна. 